\title{
Reasons for testing women for genital Chlamydia trachomatis infection in the Calgary region
}

\author{
Deirdre L Church $\mathrm{MD}^{1,2,3}$, Ali Zentner $\mathrm{MD}^{3}$, Heather Semeniuk $\mathrm{BSc}^{1}$, Elizabeth Henderson $\mathrm{PhD}^{4}$, Ron Read $\mathrm{MD}^{3}$
}

DL Church, A Zentner, H Semeniuk, E Henderson, R Read. Reasons for testing women for genital Chlamydia trachomatis infection in the Calgary region. Can J Infect Dis 2003;14(1):35-40.

OBJECTIVE: To determine the clinical reason(s) for screening women with varying degrees of risk for genital Chlamydia trachomatis $(\mathrm{CT})$ in the Calgary region.

DESIGN: Women aged 15 to 75 years were enrolled at various patient care locations. Pertinent risk factors for genital CT infection were recorded and a gynecological examination was performed. Two endocervical swabs and a first-void urine sample were collected for CT detection using two different nucleic acid amplification test methods. SETTING: Calgary is an urban region that provides healthcare services to a population of almost one million people. Microbiology services are provided by Calgary Laboratory Services through a centralized regional laboratory service.

MAIN RESULTS: 504 women with a mean age of $28.1 \pm$ SD 8.22 years were enrolled. Two hundred ninety-one women $(57.8 \%)$ were at high risk for acquiring genital CT infection. Twenty-eight (5.6\%) tested positive for CT infection and almost all of these women ( 26 of $28,93 \%)$ had risk factors for acquiring infection. Of the high-risk women, $9.8 \%$ were CT positive versus only $1.3 \%$ of women at low risk $(\mathrm{P}=0.0001)$. Only two of $152(1.3 \%)$ women older than 30 years had genital CT infections. Although most women were asymptomatic, those with laboratory-confirmed CT infection were more likely to have genitourinary symptoms. Three hundred forty-three of 476 (72\%) women who did not have genital CT infection had no risk factors, and screening was done as part of a routine gynecological examination for other purposes (prenatal visit, Pap smear).

CONCLUSION: Women without risk factors are being screened routinely for genital CT infection as part of a routine gynecological examination done for other reasons. Elimination of the routine screening of low-risk women older than 30 years of age would decrease the current regional utilization of CT tests by as much as one-third.

Key Words: Chlaymdia trachomatis; Genital infection; Screening; Women

\section{Raisons de procéder au dépistage de l'infection génitale à Chlamydia trachomatis chez des femmes dans la région de Calgary}

OBJECTIF : Déterminer les raisons cliniques justifiant le dépistage de l'infection génitale à Chlamydia trachomatis (CT) chez des femmes présentant des risques variables de maladie dans la région de Calgary.

PLAN D'ÉTUDE : Des femmes âgées de 15 à 75 ans ont été sélectionnées dans divers établissements de soins de santé. Nous avons noté les facteurs de risque pertinents d'infection à CT et avons procédé à un examen gynécologique, en plus d'effectuer deux prélèvements endocervicaux et un prélèvement d'urine du matin à la recherche de CT au moyen de deux méthodes d'amplification de l'acide nucléique.

LIEU : Calgary, région urbaine, fournit des services de santé à une population d'environ un million de personnes. Les Calgary Laboratory Services assurent la prestation des services de microbiologie par l'intermédiaire d'un laboratoire régional central.

PRINCIPAUX RÉSULTATS : Cinq cent quatre femmes (âge moyen : 28,1?ET 8,22 ans [ET : écart-type]) ont participé à l'étude, dont deux cent quatre-vingt-onze $(57,8 \%)$ connaissaient des risques élevés d'infection génitale à $\mathrm{CT}$. Nous avons enregistré 28 cas $(5,6 \%)$ confirmés d'infection à $\mathrm{CT}$, presque tous (26 sur 28; $93 \%$ ) chez les femmes exposées. Parmi les femmes à risque élevé, 9,8\% ont obtenu des résultats positifs contre 1,3\% seulement chez les femmes à faible risque $(\mathrm{P}=0,0001)$. Par ailleurs, deux femmes $(1,3 \%)$ seulement sur les 152 âgées de plus de 30 ans étaient infectées. Même si la plupart d'entre elles ne présentaient pas de symptômes, celles chez qui le test s'était avéré positif étaient plus susceptibles de manifester des symptômes génito-urinaires. Sur les 476 femmes non infectées, 343 (72\%) n'avaient pas de facteur de risque, et le dépistage de la maladie avait été effectué dans le cadre d'un examen gynécologique courant pratiqué pour d'autres motifs (consultation prénatale, test Pap). CONCLUSION : Il est usuel de procéder au dépistage de l'infection génitale à CT chez les femmes ne présentant pas de risque de maladie dans le cadre d'un examen gynécologique courant effectué pour d'autres motifs. Le fait de ne plus procéder à ce dépistage systématique chez les femmes de plus de 30 ans, peu exposées à la maladie, réduirait du tiers environ le nombre de tests effectués actuellement par le laboratoire régional.
C hlamydia trachomatis (CT) is one of the most prevalent sexually transmitted bacterial pathogens (1-4). In Canada, the rate of genital chlamydial infections stands at 112.7 of 100,000 persons and this rate is substantially higher than that of either gonorrhea or syphilis $(3,4)$. If undetected, CT genital or pelvic infection may cause ectopic pregnancy, pelvic inflammatory disease and salpingitis with secondary tubal scarring and infertility $(1,5-8)$. Women may also transmit the infection to their sexual partners and have an increased risk of acquiring HIV infection (9).

The prevalence of chlamydia infections among Canadian women varies according to the presence of risk factors/markers for the disease $(3-5,10)$. Behavioural factors such as the number of sexual partners, lack of barrier contraception and a new

These data were presented in poster form at the 99th American Society for Microbiology Meeting, Chicago, Illinois, USA

${ }^{1}$ Calgary Laboratory Services and the Departments of ${ }^{2}$ Pathology 83 Laboratory Medicine, ${ }^{3}$ Medicine, and ${ }^{4}$ Community Health Sciences, University of Calgary, Calgary, Alberta

Correspondence and reprints: Dr Deirdre L Church, Calgary Laboratory Services, 1638 10th Avenue Southwest, Calgary, Alberta T3C 0J5.

Telephone 403-209-5281, fax 403-209-5347, e-mail deirdre.church@cls.ab.ca

Received for publication October 4, 2001. Accepted February 19, 2002 
sexual partner increase the risk of acquiring chlamydia genital infection in women (1-5). Because of the nature of these risk factors, the highest prevalence of genital CT infection occurs in women between the ages of 15 and 30 years. The Laboratory Center for Diseases Control (LCDC) in Canada has published specific clinical guidelines for the appropriate screening of atrisk individuals for genital CT infection (11).

In Alberta, provincial laboratories of public health perform CT testing for provincial sexually transmitted disease (STD) clinics. Regional diagnostic laboratories such as Calgary Laboratory Services (CLS) perform the majority of all other CT tests for the general populace. Although CLS receives a high volume of genital specimens for CT testing each day (approximately 300 specimens per day), appropriate utilization of this laboratory service could not be determined because physicians rarely submitted a risk factor history. We hypothesized that previously published guidelines for CT patient risk factor assessment were not being used to appropriately screen only at-risk individuals, because many specimens from older women (more than 35 years of age) were being submitted to the laboratory. A survey of 118 family physicians in Toronto, Ontario showed that $69 \%$ of family physicians were unaware that CT guidelines existed, and even among those who had read the guidelines, 39\% did not follow them in their practice (12). Before implementing highly sensitive nucleic acid amplification technology (NAAT) for genital CT detection it was important to determine the clinical reason(s) for screening women with varying degrees of risk in our healthcare region.

\section{DATA AND METHODS}

CLS is a large, centralized, regional laboratory that provides most microbiology services to acute care hospitals, long term care facilities and outpatient locations in the community for an urban population of almost one million people. Each day, more than 2000 microbiology specimens are received for analysis, and approximately 300 of these are genital specimens for the detection of CT infection. Most of the genital specimens submitted for CT analysis are collected from women (97\%) versus men (3\%). Before the present study, CLS used an enzyme immunoassay (EIA) method with confirmation of all indeterminate and positive test results with a blocking antibody assay (Access, Beckman, Canada) and a direct fluorescent antibody assay (MicroTrak, Syva, Canada) as a routine CT test procedure. Overall, the prevalence of chlamydia cervicitis using this laboratory approach was between $2.0 \%$ and $2.5 \%$ in the Calgary health region.

The conjoint Health Research Ethics Board at the University of Calgary reviewed and gave approval to this project, and all enrolled patients signed an informed consent. All physicians in the Calgary region who routinely submitted genital specimens for CT testing to CLS were notified of the study and were asked to participate. Physicians recruited women between the ages of 15 and 75 years after they had ordered a test for CT genital infection as part of their clinical assessment. Women were enrolled from the following patient care locations: physicians' offices in the community, obstetrical and family practice clinics associated with hospitals, and emergency departments. The regional STD clinic also participated and sent samples to CLS for testing, although the public health laboratory is usually its laboratory service provider. Women attending the STD clinic represent an important control group because of their higher prevalence of CT infections and the fact that STD clinic staff members are expert at collecting genital specimens.

The patient's physician completed a clinical risk factor questionnaire that outlined the reason(s) for the patient's visit; all acute symptoms of genital infection; the patient's pertinent medical history, including all previously documented episodes of STD; a current risk factor history for acute STD infection, including CT; and all current medication use, including antimicrobial therapy. Women who were taking antibiotics or who had been on a recent course of antibiotic therapy in the month before enrolment were excluded from the analysis. A gynecological examination was performed and all clinical signs were reported on the patient's study form. Two endocervical swabs and a first-void urine sample were collected and submitted to the laboratory for CT detection by two different NAAT methods. A Pap smear was done and sent to the cytopathology laboratory. Based on their clinical and risk factor assessments, women were designated as being at risk for CT infection if they had one or more of the following risk factors/markers, as previously published by the LCDC: sexually active and younger than 25 years of age; sexually active and had contact with a known case of STD; sexually active and involved in the use of street substances; or sexually active and had a new partner or more than two partners in the previous six months (11). All women who were recruited from the regional STD clinic met the definition of being 'at risk' or 'most at risk' for urethral and/or cervical CT infection according to the LCDC criteria and were categorized as such in the analyses. Women were designated as being 'low risk' if they did not have any of the above outlined risk factors/markers for CT infection.

Separate sequential testing strategies approved by the individual commercial test suppliers were used to perform CT amplification detection methods on the two separately collected endocervical swab specimens, as previously described by Semeniuk et al (13). Physicians' collection kits were constructed so that the order of collection of endocervical swabs for the two sequential testing strategies was alternated between sequentially enrolled women. One of the endocervical swabs was placed in Gen-Probe transport medium (Gen-Probe, USA), transported at room temperature and then stored at $2^{\circ} \mathrm{C}$ to $8^{\circ} \mathrm{C}$ until it was processed. This swab was first tested using the PACE 2 assay (Gen-Probe, USA) and an aliquot taken off before performance of the PACE 2 assay was additionally tested using the AMPLIFIED-CT (AMP-CT) (TMA) assay (Gen-Probe, USA). The other endocervical swab was placed into the EIA transport tube, and was transported and stored in a similar manner. This swab was used to initially perform an EIA (Access, Beckman, Canada) and an aliquot of the EIA extract was then tested using a polymerase chain reaction method (COBAS AMPLICOR-CT, Roche Diagnostic Systems, USA). First-void urine samples were tested for CT using both the AMP-CT (Gen-Probe, USA) and COBAS AMPLICOR-CT (Roche, USA) nucleic acid amplification assays. Although first-void urine had been shown to be less 


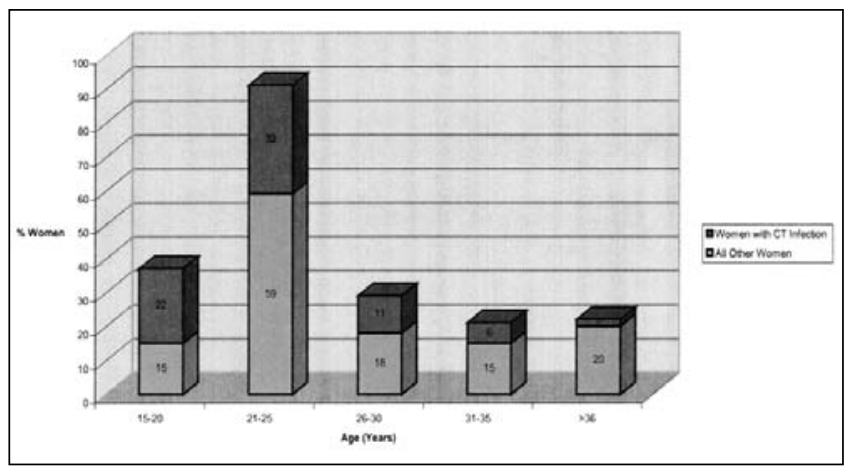

Figure 1) Age distribution of women with and without Chlamydia trachomatis infection

sensitive than endocervical swabs for detecting genital CT infection, one of the aims of the laboratory component of this study was to evaluate the performance of these two NAAT methods on each sample type at CLS $(14,15)$. Each woman thus had six separately performed laboratory tests for genital CT infection.

A true CT infection was defined as occurring in any patient who was positive on both endocervical swab nucleic acid amplification tests (PCR and AMP-CT). Because it was perceived that women with a low prevalence of CT infection were being tested (less than $5 \%$ ), it was important to use this expanded gold standard to confirm true cases $(1,16)$. Repeat testing of endocervical swab and/or the NAAT results from urine samples were used to resolve any discrepant results in each CT case between the two amplified CT methods used to test endocervical swabs.

Women were not routinely tested for Neisseria gonorrhoeae infection as part of the study unless their attending physician also collected a charcoal swab for cervical culture. Although the Canadian STD Guidelines recommend dual testing of patients who are at risk for acquiring an STD, there has been a very low prevalence of gonococcal infections reported from the Calgary region among women in the year preceding the present study (ie, the highest prevalence of 89.6 per 100,000 was found in females aged 15 to 24 years) compared with that reported for chlamydia infection rates in the same age group $(1400$ per 100,000$)(17)$.

Data were coded and entered into a statistical software program (SPSS Version 6.0 [SPSS Inc, USA] for Windows [Microsoft Corporation, USA]) and analyzed using standard descriptive methods. $\chi^{2}$ and odds ratios with $95 \%$ CI were used to compare the characteristics of women with and without genital CT infection. Fisher's exact test was used in those comparisons that had a cell value of less than five.

\section{RESULTS}

\section{Patient characteristics}

A total of 504 women participated in this study. Of these, 291 (57.7\%) were designated as being at risk for acquiring CT infection, and $255(87.6 \%)$ of these women were recruited from the regional STD clinic. Only $36(12.4 \%)$ women who had risk factors for acquiring genital CT infection were assessed at other locations (family physician or obstetrician/gynecologist office, or during an emergency

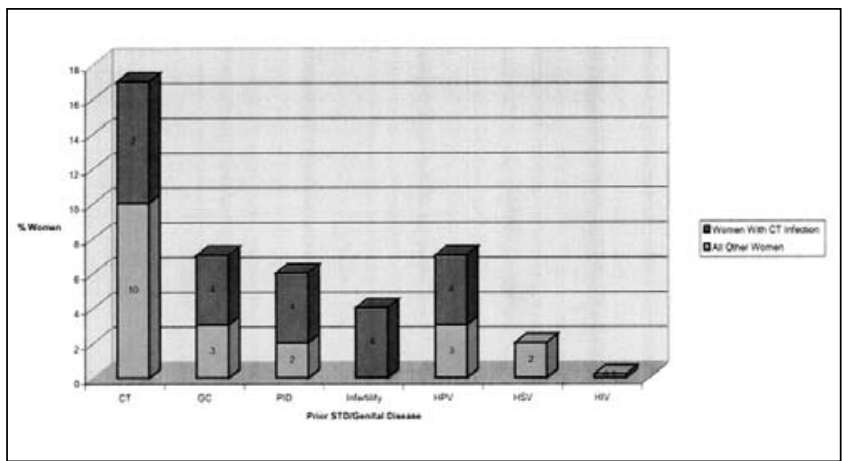

Figure 2) Past sexual history of women with and without Chlamydia trachomatis infection

department visit). The remaining 213 (42.3\%) women had no identified risk factors for acquiring genital CT infection, and all of them were assessed at locations other than the regional STD clinic. Most of these women visited either their family physician or gynecologist (84.5\%), while the rest were tested for genital CT infection as part of their physician assessment in the emergency room. However, women with confirmed genital CT infection (17 of $28,60.7 \%$ ) appeared to be more likely to be assessed at the regional STD clinic; only 11 of $28(39.3 \%)$ women were assessed by their private physician $(\mathrm{P}=0.10$, OR 2.39 , Cl 0.72 to 8.09$)$.

Of the 504 women tested, 28 women had laboratoryconfirmed genital CT infections yielding an overall prevalence rate of 5.6\% (95\% CI 3.99 to 8.51). Most of these women (26 of $28,93 \%$ ) had risk factors for acquiring CT infection. Prevalence rates were significantly different for women assessed as being at risk (9.8\%) compared with those with no risk factors for infection $(1.3 \%, \mathrm{P}=0.0001)$. Therefore, women who were at risk of acquiring CT were about 10 (OR 10.35, 95\% CI 2.35 to 63.82 ) times more likely to test positive for CT infection than those with no risk factors.

The mean age of all women tested was $28.11 \pm$ SD 8.22 years. Figure 1 shows the age distribution of CT-positive cases compared with the ages of women without genital infection. Most CT-positive cases (26 of 28, 93\%) occurred in women between the ages of 15 and 30 years, except for two women who were 31 and 41 years of age. The age was lower for women with genital CT infection with a mean of $23.77 \pm$ SE 0.95 years and a median age of $24 \pm$ SD 4.46 years. Comparison of the age distribution for women with and without genital CT infection by laboratory test method shows that a significant number of women who tested positive using the AMP-CT assay (TMA) (Gen-Probe, USA) ( $\mathrm{P}=0.04)$ were younger. The difference in age between women with and without CT infection for all other laboratory test methods also approached significance $(\mathrm{P}<0.20)$. All women who had behavioural risk factors for acquiring an STD were also younger than 30 years. There was a much wider age range among low-risk women being tested for genital CT infection, with most of these women being older than 30 years ( 152 of $213,71.4 \%$ ).

Figure 2 demonstrates the sexual history of women with genital CT infections compared with all other women. Of the 504 women tested, 79 (15.7\%) women had a previous episode of an STD. Of these, 29\% (23 of 79) of women had experi- 


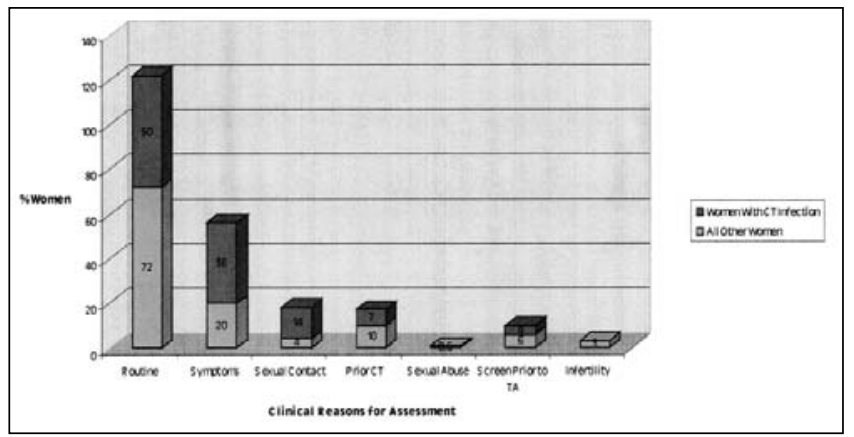

Figure 3) Clinical reasons for physicians' assessment of women

enced more than one type or episode of an STD. Comparison between women with and without CT infection who reported a history of an STD did not show a significant difference for any of the laboratory test methods. Previous CT infection (50 of $79,63.3 \%$ ) was the most common STD reported among women with and without genital CT infection. Women with a previous history of CT infection were not more likely to be CT-positive $(\mathrm{P}=0.2)$; however, women with a previous history of pelvic inflammatory disease and infertility appeared to be more likely to be CT-positive ( $\mathrm{P}=0.14)$. Past history of genital infection due to $\mathrm{N}$ gonorrhoeae was the second most common type of disease, although it occurred at one-third the rate of CT. Women with genital CT infection did not have a higher incidence of $\mathrm{N}$ gonorrhoeae compared with all other women studied. The most common genital viral disease reported was previous human papilloma virus infection and the incidence was similar in women with and without CT infection.

\section{Reasons for screening for genital CT infection}

A physician assessed these women for a variety of reasons (Figure 3). Most women in the study were completely asymptomatic for genital infection and were having a gynecological examination as part of a routine health visit for a Pap smear (343 of 476 [72\%] women without CT infection and 14 of 28 [50\%] CT-positive women). Otherwise, women were being tested because they had one or more symptoms suggestive of genital infections. Women with genital CT infection were 2.3 times more likely to be tested for this reason (94 of 476 [20\%] women without CT infection and 10 of 28 [35.7\%] women with CT infection) (OR 2.3, 95\% CI 0.94 to 5.37). Only 35 of $504(6.9 \%)$ women were being retested as a follow-up to a previous episode of genital CT infection, although most of these infections had occurred one or more years before and the patients had completed an appropriate course of antibiotic therapy. Of these, two of 35 (5.7\%) women were confirmed to have a second episode of genital CT infection. Overall, a small number of women were being tested because of a new sexual contact, sexual contact with a partner known to have an STD, or because of recent sexual abuse. Women with genital CT infection were more than three times as likely to be tested for this reason than all the other women studied (23 of 476 [4.8\%] women without CT infection and four of 28 [14.3\%] women with CT infection) (OR 3.28, 95\% CI 0.88 to 11.12). However, aside from these women being at risk for CT infection because of their age ( 15 to 30 years), half of these women were also being tested as part of a routine health visit for a Pap smear. Although women are also routinely screened for genital $\mathrm{CT}$ infection in our region before having a therapeutic abortion or treatment for infertility (ie, in vitro fertilization), only 29 of $504(5.8 \%)$ and 13 of $504(2.6 \%)$ of the women in this study were tested for these respective reasons. Only one woman with CT infection was pregnant and was scheduled to undergo a therapeutic abortion.

A comparison of the clinical symptoms reported by women with genital CT infection versus those who did not have infection is shown in Table 1. Most women were asymptomatic regardless of having genital CT infection, although those with CT were 2.6 times more likely to have had symptoms than women without CT cervicitis $(\mathrm{P}=0.2)$. Overall, $122(24.2 \%)$ women presented with symptoms of genital infection, regardless of whether they were confirmed to have CT infection. CTpositive women were significantly more likely to have vaginal discharge or odour than those without infection. Women with CT infection were also more than six times more likely to have evidence of cervicitis on examination, including cervical mucopus (ie, purulent or mucopurulent cervical discharge or cervical ectopy, $\mathrm{P}=0.00$ ).

Dysparunia, abdominal pain and irregular spotting or bleeding were much less common. Five women without genital CT infection also reported urinary frequency and/or burning with voiding as their main symptoms. Condylomata were the most common type of lesion found on genital examination of women, and sebaceous cysts, ulceration and molluscum contagiosum were reported much less frequently. None of the women with genital CT infection had any genital lesions reported.

Comparison of the reasons for testing women in our region for CT against the published guidelines shows that many of them did not meet these criteria. Only 70 (14\%) of the enrolled women were sexually active and were younger than 20 years of age. In addition, only $22(4.3 \%)$ women were 20 to 24 years of age and had either a new sexual partner and/or were not practising safer sex. Overall, 79 (15.7\%) of the 504 women had a history of a previous episode of an STD. A large proportion of women ( 152 of $504,32 \%)$ were older than 30 years of age and had no risk factors for acquiring CT infection, but were screened for infection as part of a routine health visit for a Pap smear.

\section{DISCUSSION}

Women without risks for genital CT infection in the Calgary healthcare region are being screened routinely as part of a gynecological assessment being performed for other reasons. Although physicians may have changed their usual testing behaviours as a result of paricipation in this study, the age distribution of the women recruited from the participating clinics parallels that documented by CLS as part of its daily routine laboratory practice for regional genital CT testing of women. Because a clinical history has not been required as part of ordering a genital chlamydia test in the region, physicians may have tested a larger variety of women or fewer types of women, which is a potential bias in this study.

Although many studies have established optimal strategies for testing at-risk women, few studies have focused on women with a low prevalence of infection (18-21). Howell et al (22) evaluated screening strategies for genital CT infection in 
TABLE 1

Clinical symptoms reported by women with and without chlamydia infection*

\begin{tabular}{|c|c|c|c|c|c|}
\hline Genital symptoms & $\begin{array}{l}\text { All other women } \\
(n=476)\end{array}$ & $\begin{array}{l}\text { Women with chlamydia } \\
\text { infection }(n=28)\end{array}$ & $\begin{array}{l}\text { Total in study* } \\
\qquad(n=504)\end{array}$ & $\mathbf{P}$ & $\begin{array}{l}\text { Odds ratio } \\
(95 \% \mathrm{Cl})\end{array}$ \\
\hline Vaginal discharge or odour & $43(9.0 \%)$ & $8(28.6 \%)$ & $51(10.1 \%)$ & 0.0009 & $4.03(1.52$ to 10.38$)$ \\
\hline Vaginal irritation or itchiness & $28(5.9 \%)$ & $1(3.6 \%)$ & $30(6.0 \%)$ & $1.0^{\dagger}$ & - \\
\hline Dysparunia & $6(1.3 \%)$ & - & $6(1.2 \%)$ & - & - \\
\hline Abdominal pain & $10(1.2 \%)$ & $1(3.6 \%)$ & $10(2.0 \%)$ & $0.5^{\dagger}$ & - \\
\hline Bleeding & $1(0.2 \%)$ & $1(3.6 \%)$ & $2(0.4 \%)$ & 0.11 & - \\
\hline Urinary frequency or dysuria & $5(1.0 \%)$ & - & $5(1.0 \%)$ & - & - \\
\hline Genital lesions & $18(3.8 \%)$ & - & $18(3.6 \%)$ & - & - \\
\hline Total & $84(17.6 \%)$ & $10(35.7 \%)$ & $122(24.2 \%)$ & 0.02 & $2.6(1.07$ to 6.19$)$ \\
\hline \multicolumn{6}{|l|}{ Examination } \\
\hline Cervical mucopus & $2(2.1 \%)$ & $2(7.1 \%)$ & $4(0.8 \%)$ & $0.000^{\dagger}$ & $18.2(1.75$ to 190.9$)$ \\
\hline Adenexal tenderness & $4(4.3 \%)$ & - & $4(0.8 \%)$ & - & \\
\hline Cervical motion tenderness & $2(2.1 \%)$ & $1(3.6 \%)$ & $3(0.6 \%)$ & $0.16^{\dagger}$ & \\
\hline Condylomata & $7(1.5 \%)$ & - & $7(1.4 \%)$ & - & \\
\hline Cervical ectopy & $4(4.3 \%)$ & $3(10.7 \%)$ & $10(2.0 \%)$ & $0.00^{\dagger}$ & 14.2 (2.36 to 80.76$)$ \\
\hline Total & $19(4 \%)$ & $6(2.1 \%)$ & $25(5.0 \%)$ & 0.00 & $6.56(2.1$ to 19.73$)$ \\
\hline
\end{tabular}

*Women reported more than one symptom; ${ }^{\dagger}$ Fisher's exact test

asymptomatic women attending two family practice clinics (6.6\% overall prevalence of CT infection). Universal and selective screening based on age (ie, routine screening of women younger than 30 years of age) was compared with screening on the basis of previously published risk factor criteria (12). Age-based screening combined with a risk factor assessment detected almost as many CT cases as the universal screening of all women. Another study among female adolescents aged 15 to 19 years supports screening at-risk young women at each health visit, even if previous test results for CT infection were negative and risk factors are absent (23). Most of the women enrolled in our study were also appropriately tested for genital CT infection using this age-based plus risk factor assessment approach.

The present study also validates that the LCDC risk factor/marker criteria for genital CT infection may be used to target the testing of at-risk women using highly sensitive NAAT methods to detect genital CT infection in women (11). Although Canadian STD guidelines for screening have largely been based on the detection of genital CT infection using EIA methods, all of the women who tested positive using highly sensitive NAAT methods had one or more risk factors/markers for acquiring an STD, and amplified test methods were confirmed to be much more sensitive than EIA in detecting CT infection (13).

Due to the very low prevalence of CT infection in women older than 30 years of age in Calgary, routine testing of this group is neither clinically nor economically justifiable. A total of $152(32 \%)$ women were enrolled in the older age groups, and only two (31 and 41 years of age) were detected to have genital CT infection using highly sensitive laboratory methods. Older women should only be tested for CT infection if they are clinically deemed to be at risk according to previously published guidelines (11). More discriminate testing of older women for genital CT infection in the Calgary region would eliminate up to one-third of the current volume of daily tests performed by our laboratory ( 80 to 100 CT tests).
Establishing the appropriate utilization of genital CT screening of women in our region would not only save healthcare resources, but would also allow highly sensitive NAATs to be applied more appropriately to individuals with the highest risk of infection. It has been well documented that a higher number of false-positive tests occur when NAAT technology is used to test low prevalence populations for CT infection (16). Because a clinical history is often not provided on the test requisition, it is not feasible for diagnostic laboratories to deploy appropriate CT testing strategies based on an assessment of infection risk. Laboratories could, however, implement a policy of not performing a CT test on women older than 30 years of age unless the physician provides a risk factor assessment.

Population-based studies such as the present one need to be done in other healthcare regions in Canada to evaluate current physician utilization practices for testing women for CT infection. If clinical practice is similar across the country, eliminating the routine testing of older women for CT infection could save a significant amount of money. This money could be diverted to the appropriate screening by highly sensitive amplification CT tests of at-risk subpopulations (ie, street youth, adolescents) with the highest prevalence $(24,25)$. However, the appropriate utilization of CT tests can only be achieved through improved physician education. Physicians must also have access to published clinical guidelines to perform a standardized risk factor assessment before ordering a CT test. The results of this study are being used to encourage more appropriate CT test utilization in our region.

ACKNOWLEDGEMENTS: The authors thank the staff at the regional sexually transmitted diseases clinic in Calgary, Alberta; and the emergency departments, obstetrics and gynecology clinics, family planning clinics and family physician offices for their tireless support of this study. This research was supported by Beckman (Missisauga, Ontario), Gen-Probe (San Diego, California, USA) and Roche (Roche Diagnostic Systems, Branchburg, New Jersey, USA). 


\section{REFERENCES}

1. Black CM. Current methods of laboratory diagnosis of Chlamydia trachomatis infection. Clin Microbiol Rev 1997;10:160-84.

2. Stamm WE. Chlamydia trachomatis infections: progress and problems. J Infect Dis 1999;179(Suppl 2):S380-3.

3. Peeling RW, King L. Sexually transmitted diseases: Impact of molecular laboratory diagnostic methods on disease control and prevention. Can J Infect Dis 1999;10:387-90.

4. Health Canada. Notifiable Diseases Summary. Can Commun Dis Rep 1999;25:174.

5. Davies HD, Wang EE. Periodic Health Examination, 1996 update: 2. Screening for chlamydial infections. CMAJ 1996;154:1631-44.

6. Cates W Jr, Wasserheit JN. Genital chlamydial infections: epidemiology and reproductive sequelae. Am J Obstet Gynecol 1991;164:1771-81.

7. Pearlman MD, McNeeley SG. A review of the microbiology, immunology, and clinical manifestations of Chlamydia trachomatis infections. Obstet Gynecol Surv 1992;47:448-61.

8. Scoles D, Stergachis A, Heidrich FE, Andrilla H, Holmes KK, Stamm WE. Prevention of pelvic inflammatory disease by screening for cervical chlamydial infection. N Engl J Med 1996;334:1362-6.

9. Wasserheit JW. Epidemiological synergy: interrelationships between HIV infection and other STDs. In: Chen LC, Amor JS, Segal SJ, eds. AIDS and Women's Reproductive Health. New York: Plenum Press, 1991:7-72.

10. Gully P, Rwetsiba DK. Chlamydial infection in Canada. CMAJ 1992;147:893-6.

11. Laboratory Centre for Disease Control Expert Working Group on Canadian Guidelines for Sexually Transmitted Diseases. Canadian STD Guidelines, 1998. Ottawa: Minister of Public Works and Government Services Canada, 1998.

12. Weyman D, Lansing AR. Screening guidelines for Chlamydia trachomatis infection. Can Fam Physician 1995;41:228-36.

13. Semeniuk H, Zentner A, Read R, Church DL. Evaluation of sequential testing strategies using non-amplified and amplified methods for detection of Chlamydia trachomatis in endocervical and urine specimens from women. Diagn Micro Inf Dis 2002;42:43-51.

14. Ferraro DV, Meyers HN, Schultz DE, Willis SA. Performance of the Gen-Probe AMPLIFIED Chlamydia trachomatis assay in detecting Chlamydia trachomatis in endocervical and urine specimens in women and urethral and urine specimens from men attending sexually transmitted disease and family planning clinics. J Clin Microbiol 1998;36:3230-3.
15. Lauderdale T-L, Landers L, Thorneycroft I, Chapin K. Comparison of the PACE-2 assay, two amplification assays and clearview EIA for detection of Chlamydia trachomatis in female endocervical and urine specimens. J Clin Microbiol 1999;37:2223-9.

16. Black CM. "But Doctor, I'm Celibate!" The potential for, sources and implications of false-positive (and negative) results for tests for Chlamydia trachomatis. Clin Microbiol News 1998;20:120-4.

17. Alberta Health. Sexually Transmitted Diseases in Alberta. Epidemiologic Report to December 1997 Health Surveillance Branch, Alberta Health and Wellness, Edmonton, Alberta, 1998.

18. Mahony JB, Luinstra KE, Sellors JW, et al. Role of confirmatory PCRs in determining performance of Chlamydia Amplicor PCR with endocervical samples from women with a low prevalence of infection. J Clin Microbiol 1994;32:2490-3.

19. Skulnick M, Chua R, Simor AE, et al. Use of the polymerase chain reaction for the detection of Chlamydia trachomatis from endocervical and urine specimens in an asymptomatic lowprevalence population of women. Diagn Microbiol Infect Dis 1994;20:195-201.

20. Dean D, Ferrero D, McCarthy M. Comparison of performance and cost-effectiveness of direct fluorescent-antibody, ligase chain reaction, and PCR assays for verification of chlamydial enzyme immunoassay results for population with a low to moderate prevalence of Chlamydia trachomatis infection. J Clin Microbiol 1998;36:94-9.

21. Masse R, Laperriere H, Rousseau H, Lefebvre J, Remis RS. Chlamydia trachomatis cervical infection: prevalence and determinants among women presenting for routine gynecologic examinations. CMAJ 1991;145:953-61.

22. Howell MR, Quinn TC, Graydos CA. Screening for Chlamydia trachomatis in asymptomatic women attending family planning clinics. A cost-effectiveness analysis of three strategies. Ann Intern Med 1998;128:277-84.

23. Mosure DJ, Berman S, Kleinbaum D, Halloran ME. Predictors of Chlamydia trachomatis infection among female adolescents: A longitudinal analysis. Am J Epidemiol 1996;144:997-1003.

24. Gerc M, Mardh P-A. A cost-effectiveness analysis of screening and treatment for Chlamydia trachomatis infection in asymptomatic women. Ann Int Med 1996;124(1 pt 1):1-7.

25. Miller WC. Screening for chlamydial infection. A model program based on prevalence. Sex Trans Dis 1998;25:201-10. 


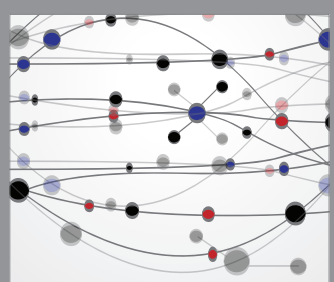

The Scientific World Journal
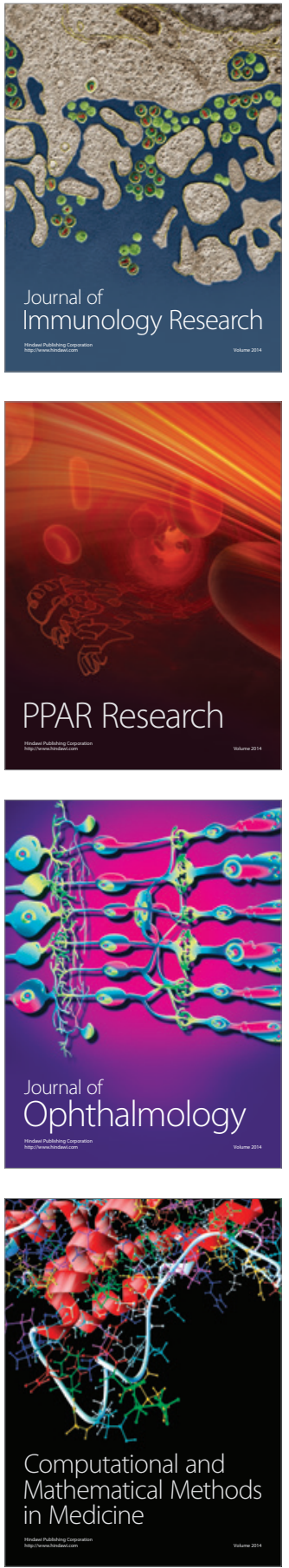

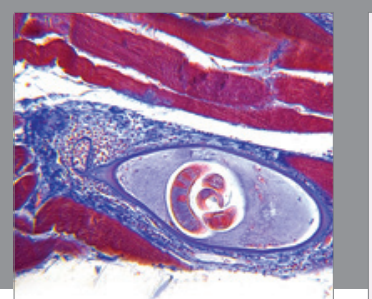

Gastroenterology Research and Practice

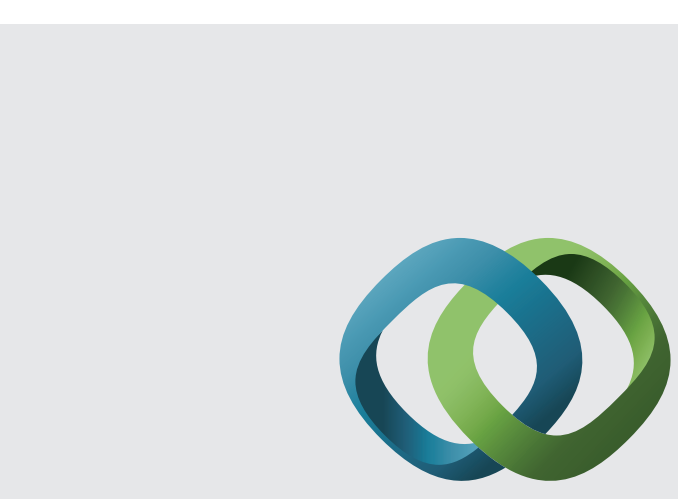

\section{Hindawi}

Submit your manuscripts at

http://www.hindawi.com
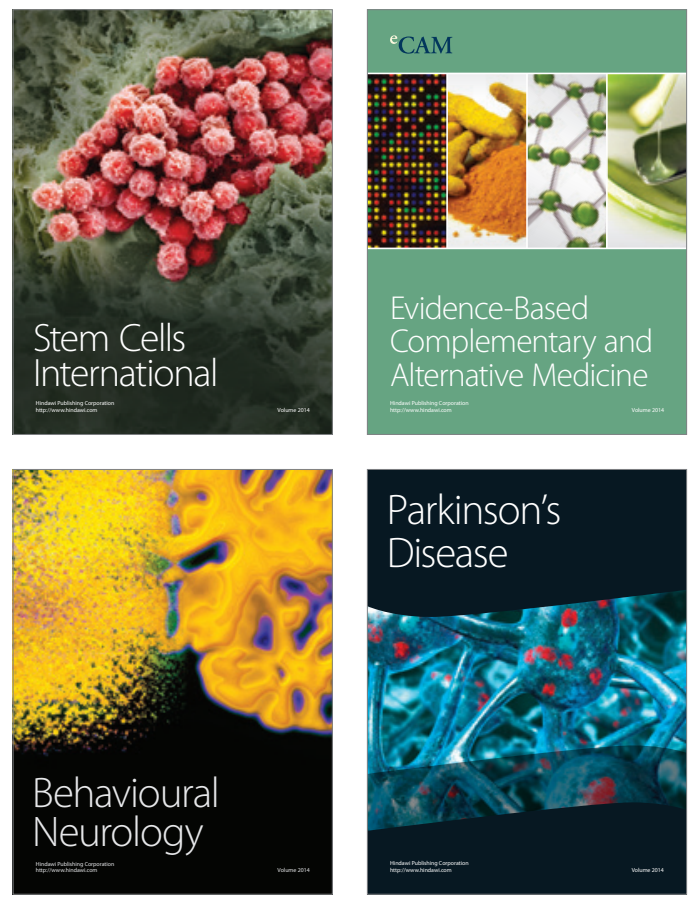
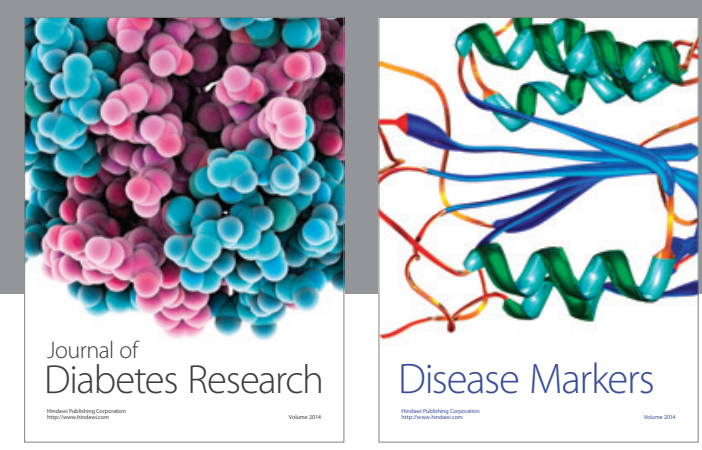

Disease Markers
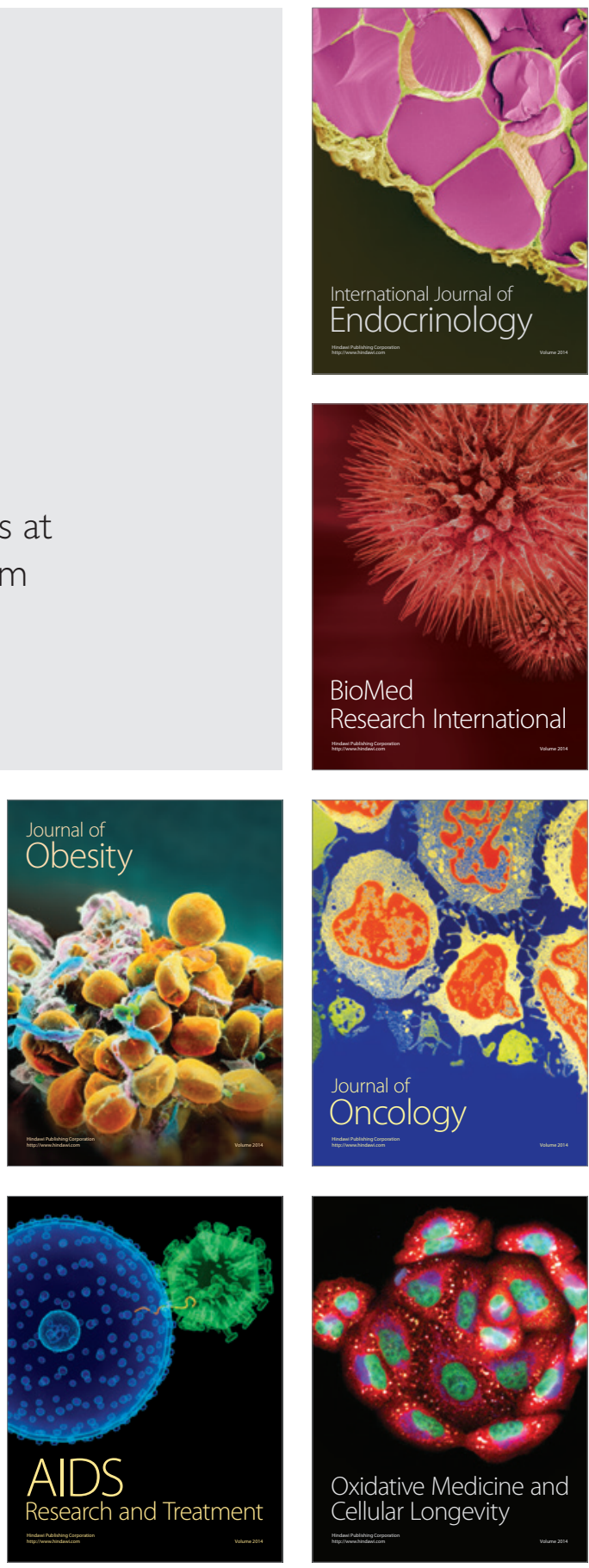